\title{
How to do a research fellowship in psychiatry in the USA
}

\author{
Séamus Ó Flaithbheartaigh
}

This citicle offors sugcestions to poychlatilc trainees who might be interested in spending a period of training in the USA, Including Ideces cobout employment, qualincations, diflerences in practice, and useful addresess and sources of information.

Stuck in the trough between registrar and senior registrar? Wanting to complete some research, or to experience psychiatric practice in another country? Why not spend some time in the USA and in the process distinguish yourself for that SR job you so badly want.

\section{How to start}

I moved to New York City one year ago. I had been a registrar in South Wales and had already passed the MRCPsych. I wished to obtain research experience, and felt America offered more opportunities for this. Having decided to spend some time in the USA, my options were to start a residency programme lasting four years similar to the one I had just completed, or to seek a fellowship in which I could engage in full-time research. I felt the latter offered more opportunitles to gain new skills, and if in an in-patient research unit, to retain clinical skills.

My first consideration in planning my way was to take a visa-qualifying examination. currently the US Medical Licensure Examination (USMLE). Full information on this is available from the Educational Commission for Foreign Medical Graduates (ECFMG: see Useful Addresses below). Anyone interested in clinical work in the USA should consider sitting this examination as early as possible. The first part may be taken while still in medical school. Planning is essential here as foreign doctors must gain both the basic medical sciences and the clinical part of the USMLE, and the examinations are only held twice a year.
The best source of information on the varied specialities and on the relevant training programmes is the current Graduate Medical Education Directory (American Medical Association, 1993), available in major medical libraries as well as in the American Embassy library. It is always worth enquiring locally for contacts in American psychiatry, as this could both make the task easier and provide an Insider view of the centre. Most major American hospitals have an overseas or visa office, which gives information to prospective trainees as well as sponsoring the candidates' visa applications. An informattve booklet is also generally available for the speciality, listing departmental activities and facilities, describing the educational programme and faculty and describing research activity.

I visited New York five months prior to my move, after first writing and sending a curriculum vitae to the psychiatry departments of several medical centres. I recetved responses to my enquiries only when I followed them up with telephone calls. Each department agreed to see me after I explained my interest in taking a research fellowship in psychiatry. I visited two departments, both of which offered me positions. Having decided to accept a position in Mount Sinal Hospital in New York City, it took several months to complete documentation with the ECFMG, and then several weeks more for the hospital administration to officially make an appointment.

\section{Visas}

Two main categories of visa are applicable to foreign medical trainees coming to the US, the $J-1$ visa and the H-1B visa. ECFMG deals with the visa qualification examination, and issues the IAP-66 form, which certifies eligibility for visa insurance. Clinical $J$ visas, the main category available to foreign medical trainees who are aliens, have certain restrictions 
including difficulty in later changing to an immigrant visa if wished, and usually involving a return to the home country at the end of training for two years before issuing another visa. Exceptions to this 'two year rule' include those who are in non-federally funded positions and are not involved in direct patient care. For detalled information it is worth consulting with the visa section of the American embassy.

The H-1B visa category has recently been made available to medical trainees. One is more likely to recetve this visa after passing a visa-qualifying examination. The two-year rule does not apply with it. Processing for a $\mathrm{H}$ visa may take some time and in my case I decided to change my application to one for a $\mathrm{J}$ visa because of the long delays.

\section{Training and eraminations}

There are some interesting differences in medical and psychiatric training in the US from the situation in the UK and Ireland. In the US, a prospective physician will enter untversity to complete a four year degree, but will need course credits in sciences to fulfil premedical requirements. University graduates then apply to medical school, a four year postgraduate course. To specialise after graduation one enters a residency programme, usually for four more years including the intern (first) year. Foreign graduates take the new USMLE both to enter the US as a medical trainee and, when they complete the final component, to obtain a state licence. This examination replaces a series of previous examinations for both purposes, and full information is available from ECFMG. States will specify the number of years of US postgraduate training required to obtain a full medical license, ranging from one to three (usual). Many states will recognise some hospital training obtained abroad for part of this period. Information on the regulations of the individual states, as well as their addresses, can be obtained from the Federation of State Medical Boards.

If you are planning to stay in America and seeking a medical college or other senior positions, it may be worth taking the examinations of the American Board of Psychiatry and Neurology (see Information for Applicants booklet, ABPN, 1993). Those with training completed up to MRCPsych level in the UK, as well as those with certain other foreign training, can have credit granted for this training and thus become eligible to sit the ABPN examinations. However, after 1997 ABPN examination candidates will be required to have completed an accredited US or Canadian residency (The American Board of Psychiatry and Neurology, 1993). There is no necessity such as exists in the UK to complete speciality examinations to enter independent practice, but many job advertisements specify "Board Certified or Board Eligible" (BC/BE), meaning those who have passed the ABPN examination or fulfilled the board's criterla for entry to the examination respectively.

\section{Senior training}

It is possible to obtain a research post without the USMLE or other examination, but psychiatrists may miss the advantages of direct clinical contact. Another consideration for those contemplating an extended stay is that working in a post not offictally recognised as residency training may put gaining a full medical licence out of reach. Fellowships are optional after completion of residency, can be clinical or research-oriented and last from one to several years. Many cover highly specialised fields. I chose to work in a schizophrenia fellowship, in a large research department. At fellowship level there is scope to structure one's own activity, but I found not having a formal job description as frequently happens here can lead to delays in assignment to specific projects and supervisors.

\section{What kind of hospital?}

There are three principal types of hospitals in the US which cater for psychiatric patients. Prtvate hospitals include many large hospitals cum medical schools. Veterans' Administration (VA) hospitals, which are federally funded are often affliated to medical schools and recruit trainees through them. The above two serve many specialities besides psychiatry. Third, State Hospitals are run by the individual states and serve mainly long-stay psychiatry patients. There are also state untversity medical centres, and some of these are well respected research centres.

\section{Comment}

A period spent working in the US, if planned with care, can offer interesting professional 
experience and open up new possibilities both back home or by staying in the US. In spite of the barriers to mutual recognition of training and the necessity for further examinations, US examinations are probably no more difficult than the equivalent British and Irish qualifications. US residencies in psychiatry generally last only four years, after which a psychiatrist is "fully trained". With the MRCPsych, foreigners may only need one to two years' training to gain State and speciality recognition. Hospitals often sponsor successful residents who wish to stay on the staff for immigration visas.

\section{Useful addresses}

Order Department OP416793, American Board of Psychiatry and Neurology, Inc., 500 Lake Cook Road, Suite 335, Deerfield, minois 60015, USA.

American Medical Association, PO Box 109050, Chicago, IL 60610-9050, USA.
Educational Commission for Foreign Medical Graduates, 3624 Market Street, Philadelphia, Pennsylvania 19104, USA.

Embassy of the United States, 5 Upper Grosvenor Street, London W1A 2JB.

Embassy of the United States, 42 Elgin Road, Ballsbridge, Dublin 4, Ireland.

The Federation of State Medical Boards of the United States, Inc., 6000 Western Place, Suite 707, Fort Worth, Texas 76107, USA.

\section{References}

AMIERICAN BOARD OF PSYCHATRY AND NEUROLOGY (1993) Information for Applicants. Deerfield, IL: ABPN.

American Medical Associntion (1993) Graduate Medical Education Dtrectory 1993-1994. Chicago, IL: American Medical Assoclation.

Séamus Ó Flaithbheartaigh, Bronx VA Medical Center, Department of Psychiatry, \#116 A, 130 West Kingsbridge Road, Bronx, New York 10468, USA

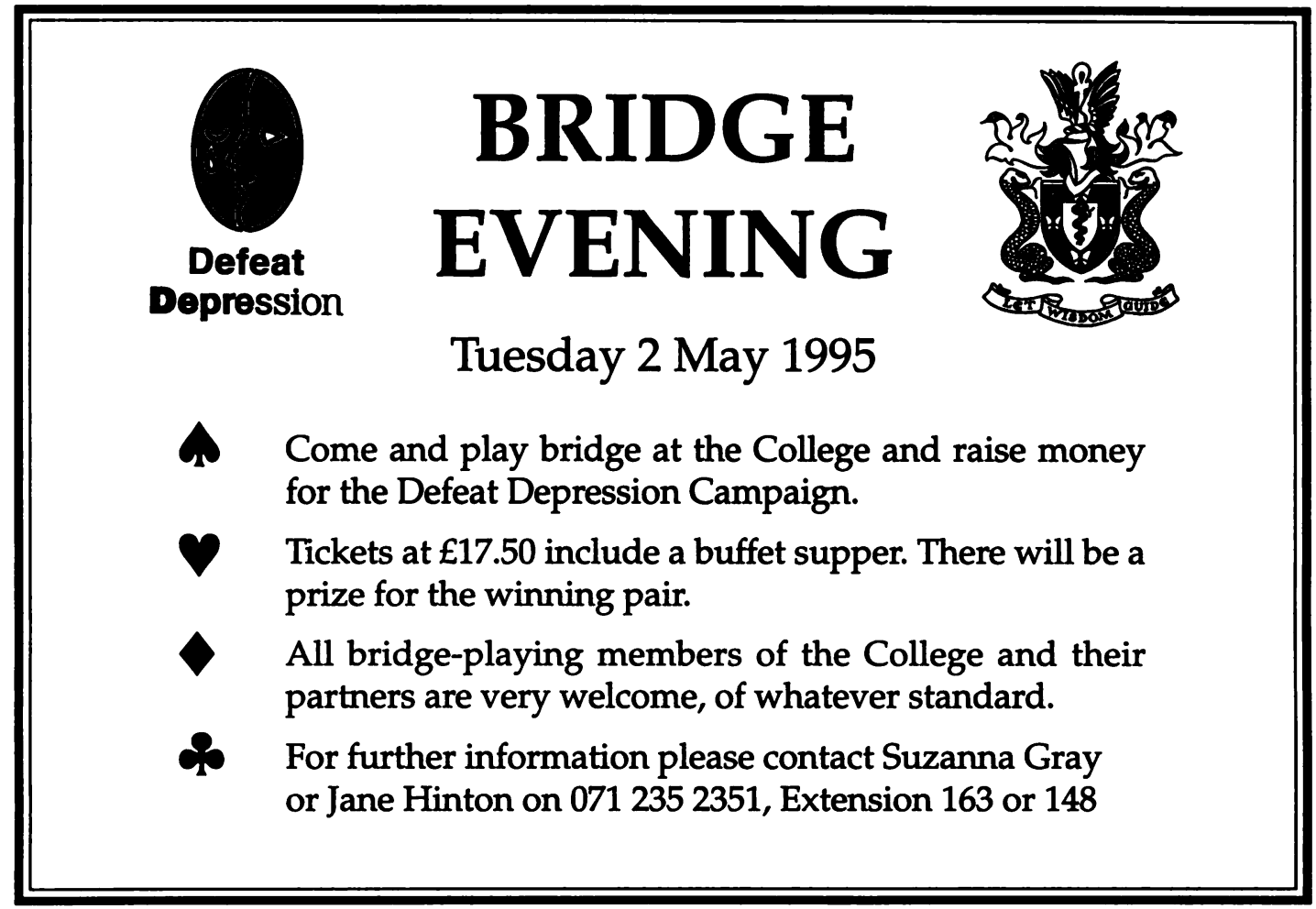

